\title{
Goldberg-Shprintzen Syndrome Associated with a Novel Variant in the KIFBP Gene
}

\section{Pelin Ozyavuz Cubuk}

Department of Medical Genetics, Haseki Training and Research Hospital, Health Sciences University, Istanbul, Turkey

\section{Established Facts}

- Goldberg-Shprintzen syndrome (GOSHS) is associated with KIFBP gene mutations.

- To date, 16 different biallelic KIFBP mutations have been identified in 34 patients with GOSHS.

\section{Novel Insights}

- This novel homozygous frameshift deletion mutation in the last exon of the KIFBP gene provides enrichment of mutational databases.

- This is the closest mutation to the $3^{\prime}$-UTR of the gene in the last exon and contributes to the understanding of the phenotypic features of the syndrome

\section{Keywords}

KIFBP · Novel mutation · Megacolon

\begin{abstract}
Goldberg-Shprintzen syndrome (GOSHS) is characterized by microcephaly, developmental delay, dysmorphic features, Hirschsprung disease (HSCR), and brain anomalies. The kinesin family binding protein (KIFBP; MIM 60937) gene has been identified as the responsible gene of the syndrome. To date, 16 different biallelic KIFBP mutations have been identified in 34 patients with GOSHS. Even though most of these mutations are nonsense and frameshift, 3 missense mutations have also been described. Here, we report an 18-month-old patient with microcephaly, developmental delay, dysmorphic features and HSCR. Exome analysis was performed to
\end{abstract}

clarify the etiology of the clinical features. A previously unreported homozygous c.1723delC (p.H575lfs*19) variant was detected in the last exon 7 of KIFBP which led to GOSHS. According to our findings, we suggest that this mutation expands mutational databases and contributes to the understanding of the phenotypic features of the syndrome.

(c) 2021 S. Karger AG, Basel

\section{Introduction}

Goldberg-Shprintzen syndrome (GOSHS; 609460) is an autosomal recessive disease characterized by intellectual disability, gyral abnormalities, Hirschsprung disease (HSCR), and dysmorphic facial features. It was first described by Goldberg and Shprintzen [1981]. The KIFBP 
Table 1. Clinical and molecular features of the GOSHS patients

\begin{tabular}{|c|c|c|c|c|c|c|c|c|}
\hline Exon & KIFBP variant protein & Case & Refererence & $\begin{array}{l}\text { Aganglionic } \\
\text { megacolon }\end{array}$ & $\begin{array}{l}\text { Brain } \\
\text { malformation }\end{array}$ & $\begin{array}{l}\text { Developmental } \\
\text { delay }\end{array}$ & $\begin{array}{l}\text { Micro- } \\
\text { cephaly }\end{array}$ & $\begin{array}{l}\text { Dysmorphic } \\
\text { features }\end{array}$ \\
\hline 1 & Glu84* & 4 & Hurst, 1988 & 3 & 4 & 4 & 4 & 4 \\
\hline 1 & Arg90* & 5 & Brooks et al., 1999, 2005; Drevillion et al., 2013 & 4 & 5 & 5 & 4 & 5 \\
\hline $2-3$ & Asn $143 \mathrm{fs} \mathrm{X} 1$ & 2 & Valence et al., 2013 & - & 2 & 2 & 2 & 1 \\
\hline 3 & Pro189Ser & 1 & MacKenzie et al., 2020 & 1 & 1 & 1 & 1 & 1 \\
\hline 3 & Ser $200^{*}$ & 2 & Drevillion et al., 2013 & 2 & 2 & 2 & 2 & 2 \\
\hline 3 & Arg202Ilefs*2 & 2 & Drevillion et al., 2013 & 1 & 2 & 2 & 2 & 2 \\
\hline 4 & Glu240* & 2 & Brooks et al., 2005 & 1 & 2 & Not available & 1 & 2 \\
\hline $5-6$ & EX5-6DEL & 3 & Dafsari et al., 2015; MacKenzie et al., 2020 & 2 & - & 3 & 3 & \\
\hline 6 & EX6 DEL & 2 & MacKenzie et al., 2020 & 1 & 1 & 2 & 2 & \\
\hline 6 & $\mathrm{G} \ln 326^{*}$ & 1 & Salehpour et al., 2017 & 1 & 1 & 1 & 1 & 1 \\
\hline 7 & Ala373Asnf*17 & 2 & Murphy et al., 2006 & - & 2 & 2 & 2 & 1 \\
\hline 7 & Ser427Gly & 1 & MacKenzie et al., 2020 & - & 1 & 1 & 1 & - \\
\hline 7 & Tyr466X & 1 & Bruno et al., 2011 & 1 & - & 1 & 1 & 1 \\
\hline 7 & Ile506Asnfs*3 & 2 & MacKenzie et al., 2020 & 1 & 1 & 2 & 2 & 2 \\
\hline 7 & Gln518Asnf*11 & 2 & Goldberg and Shprintzen, 1981 & 2 & 2 & 2 & 2 & 2 \\
\hline 7 & Glu565 AsnfX15 & 1 & MacKenzie et al., 2020 & 1 & 1 & 1 & 1 & 1 \\
\hline \multirow[t]{2}{*}{7} & H575Ifs*19 & 1 & Present case & 1 & 1 & 1 & 1 & 1 \\
\hline & & 34 & & $22 / 34(64 \%)$ & $28 / 34(82 \%)$ & $32 / 34(94 \%)$ & $32 / 34(94 \%)$ & $\begin{array}{l}26 / 34 \\
(76 \%)\end{array}$ \\
\hline
\end{tabular}

gene was identified by Brooks et al. [2005] revealing homozygous mutations which caused GOSHS. The KIFBP gene encodes a KIF-binding protein (KBP) which is expressed in the central and enteric nervous systems [Drévillon et al., 2013]. KBP dysfunction affects neuronal migration, axonal extension, and neuronal apoptosis; therefore, it is thought to cause brain anomalies in patients with GOSHS [Chang et al., 2019]. Most patients also have HSCR, which is caused by a delay or arrest of enteric neural crest cell migration [Webster, 1973]. To date, 16 different KIFBP mutations have been described in patients with GOSHS, the clinical findings of these 34 patients are summarized in Table 1 [Hurst et al., 1988; Brooks et al., 1999, 2005; Murphy et al., 2006; Bruno et al., 2011; Drévillon et al., 2013; Dafsari et al., 2015; Salehpour et al., 2017; MacKenzie et al., 2020].

In this current case report, we present an 18-monthold patient with GOSHS associated with a novel homozygous variant in the last exon of KIFBP.

\section{Clinical Report}

A 3-month-old female patient presented to our clinic with dysmorphic facial findings and developmental delay. She was born by normal vaginal delivery at term as the first child of her parents who were first-degree cousins. Birth weight (3,300 g, 50th percentile), birth height (50 cm, 50th percentile), and head circumference (33 $\mathrm{cm}, 10$ th-25th percentile) were normal. At birth, she had hypoto- nia and dysmorphic facial features including hypertelorism, downslanting palpebral fissures, and a preauricular skin tag. She had feeding difficulties when she was 2-days-old, and bilious vomiting and no stool production were observed on day 7.

Abdominal ultrasound imaging showed dilated bowel loops; the clinical findings and radiologic studies were considered as intestinal malrotation. During surgery, the cecum was at the upper right quadrant of the abdomen and Meckel's diverticulum was detected. The small intestines were observed to be highly dilated due to the obstructive occlusion. A meconium plug was removed, and an ileostomy was performed at the level of the terminal ileum. Ganglion cells were not seen in the pathologic specimen examination.

Two months later, she underwent surgery for a second time due to small bowel perforation. The posterior fossa was found as small in transfontanelle ultrasound imaging.

When she was aged 3 months, her physical examination was as follows: weight $3,550 \mathrm{~g}$, height $53 \mathrm{~cm}$, head circumference $33.5 \mathrm{~cm}$. Dysmorphic features were sparse hair, microcephaly, acrobrachycephaly, metopic ridge, ptosis, hypertelorism, downslanting palpebral fissures, and a thick philtrum (Fig. 1). Furthermore, she had severe hypotonia, and her developmental milestones were delayed. In an examination at age 10 months, failure to thrive and microcephaly were additional findings, and her weight was $5,850 \mathrm{~g}(<3 \mathrm{rd}$ percentile), height $65 \mathrm{~cm},(<3 \mathrm{rd}$ percentile), and head circumference $36.5 \mathrm{~cm}$ (<3rd percentile). She was unable to hold her head up. Brain MRI revealed cerebral atrophy in the parietal and occipital lobes and pachygyria. No epileptic discharge was observed in her EEG. An eye examination revealed bilateral lower oblique hyperfunction and poor object tracking. Large copy number variations were excluded with chromosomal microarray (CytoScanOptima Suite, Affymetrix). Exome sequencing was performed using the IDT xGEN Exome Research Panel on an Illumina Nova- 
Fig. 1 Facial dysmorphic features of the patient. a Sparse hair, metopic ridge, hypertelorism. b Downslanting palpebral fissures, thick philtrum, and tented upper lip.
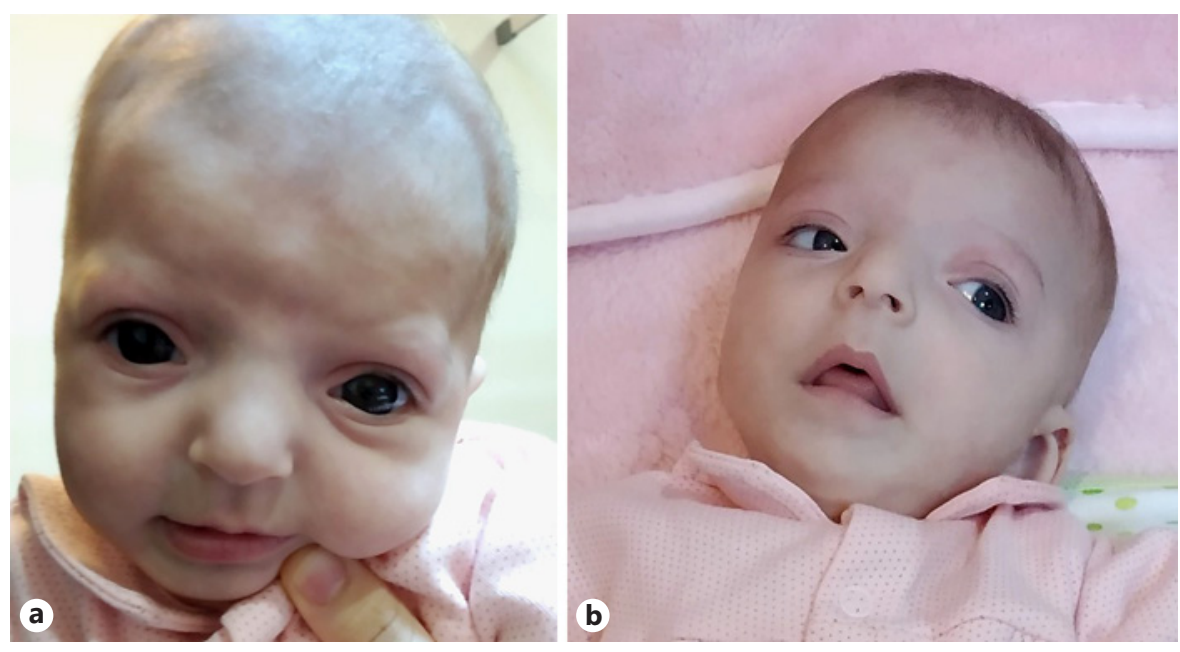

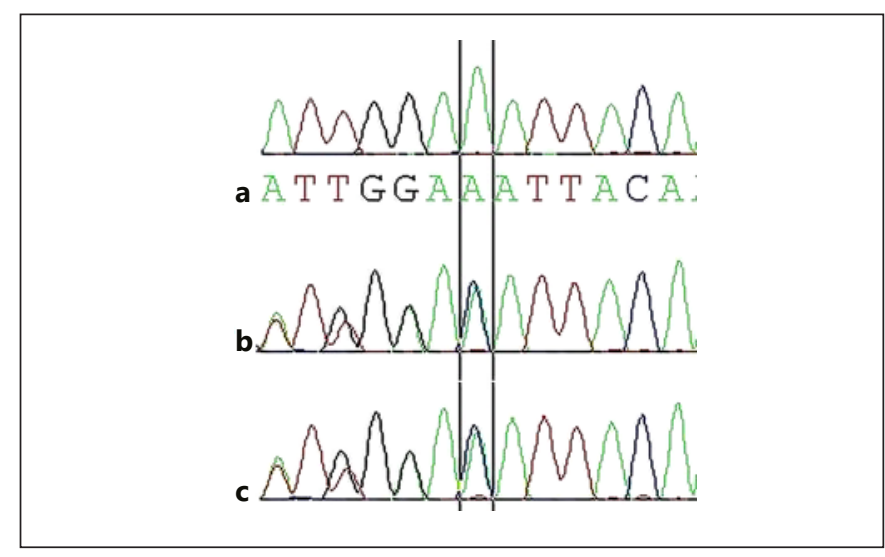

Fig. 2 Sanger sequencing analysis of KIFBP gene variants. a Proband with homozygous deletion. $\mathbf{b}$ Mother of the proband with heterozygous deletion. c Father of the proband with heterozygous deletion.

Seq platform. The variants were evaluated according to ACMG2015 [Richards et al., 2015]. Analysis revealed a likely pathogenic novel homozygous deletion variant c.1723delC (p.H575Ifs*19) in the last exon of the KIFBP (NM_015634.3) gene. This frameshift deletion was closer to the $3^{\prime}$-UTR region than in previously reported 16 KIFBP mutations. Segregation analysis revealed both parents were in the heterozygous state, which validates the transmission from the parents to the proband (Fig. 2).

\section{Discussion}

GOSHS is a rare disease caused by homozygous mutations in the KIFBP gene. To date, 16 different KIFBP gene mutations have been reported in 34 patients, most of which were nonsense and frame-shift mutations leading to loss of
KBP function (Table 1). In our case, we describe a female patient with microcephaly, dysmorphic facial findings, developmental delay, HSCR, and cerebral atrophy carrying a novel homozygous frameshift deletion variant in the last exon of the KIFBP gene. Microcephaly, central nervous system findings, HSCR, distinctive facial features, and developmental delay are the main features of the syndrome and are present in most patients with GOSHS.

Microcephaly, reported in 32 of the previous 34 patients with GOSHS, is the most common finding of the disease and accompanies other brain anomalies in most patients, especially polymicrogyria and cerebral atrophy. These anomalies usually cannot be diagnosed in early cranial imaging; nevertheless, cranial MRI was performed in our patient with microcephaly at the age of 10 months, and cerebral atrophy was detected; however, because gyrus anomalies could not be detected, they could not be ruled out.

HSCR is generally recognized with meconium plug syndrome and intestinal obstruction in the neonatal period and may accompany Meckel's diverticulum, as in our patient. HSCR was reported in 22 of 34 patients with mutations in the KIFBP gene, suggesting that there is a lack of penetrance for HSCR. However, HSCR may not be present in every patient, thus gastrointestinal findings differ among individuals with KIFBP mutations.

Genetic syndromes in which HSCR is the main symptom include GOSHS and Mowat-Wilson syndrome. Although these 2 syndromes have common findings such as microcephaly, intellectual disability, and HSCR, they differ from each other by facial features and molecular diagnoses. In our case, exome analysis allowed a simultaneous search of variants in many genes that led to similar phenotypic findings and allowed us to reach a diagnosis more quickly. 
Hypertelorism and prominent ears are the most common distinctive dysmorphic features reported in patients with GOSHS, accompanying developmental delay occurs in $94 \%$ of all the patients. Our patient's facial features were similar to those previously reported in patients with GOSHS. Hypotonia, microbrachycephaly, hypertelorism, and short philtrum were the most prominent dysmorphic features of the current case. Although not previously reported in patients with GOSHS, she had bilateral pre-auricular skin tags, which were considered an incidental finding because they were also present in her grandfather.

In conclusion, we present a patient with microcephaly, cerebral atrophy, developmental delay, dysmorphic facial features, and HSCR, and define a new homozygous frameshift deletion mutation in the last exon of the KIFBP gene. This is the first Turkish patient with GOSHS in the literature.

\section{Acknowledgements}

We thank the patient and her family for participating in this study, and we acknowledge Mehmet Bugrahan DUZ (Department of Medical Genetics, Haseki Training and Research Hospital, Istanbul) for critical reading of the manuscript.

\section{Statement of Ethics}

This study was performed in accordance with the Declaration of Helsinki Principles. Written informed consent was obtained from the patient's parents for the publication of this case report and accompanying images.

\section{Conflict of Interest Statement}

The author has no conflict of interest to declare.

\section{Funding Sources}

There are no funding sources to report.

\section{Author Contributions}

The current case report was designed and written by Pelin Ozyavuz Cubuk. The data was collected by Pelin Ozyavuz Cubuk.

\section{References}

Brooks AS, Breuning MH, Osinga J, vd Smagt JJ, Catsman $\mathrm{CE}$, Buys $\mathrm{CH}$, et al. A consanguineous family with Hirschsprung disease, microcephaly, and mental retardation (GoldbergShprintzen syndrome). J Med Genet. 1999; 36(6):485-9.

Brooks AS, Bertoli-Avella AM, Burzynski GM, Breedveld GJ, Osinga J, Boven LG, et al. Homozygous nonsense mutations in KIAA1279 are associated with malformations of the central and enteric nervous systems. Am J Hum Genet. 2005;77(1):120-6.

Bruno DL, Stark Z, Amor DJ, Burgess T, Butler K, Corrie S, et al. Extending the scope of diagnostic chromosome analysis: detection of single gene defects using high-resolution SNP microarrays. Hum Mutat. 2011;32(12):15006.

Chang HY, Cheng HY, Tsao AN, Liu C, Tsai JW. Multiple Functions of KBP in Neural Development Underlie Brain Anomalies in Goldberg-Shprintzen Syndrome. Front Mol Neurosci. 2019;12:265.
Dafsari HS, Byrne S, Lin JP, Pitt M, Jongbloed JD, Flinter F, et al. Goldberg-Shprintzen megacolon syndrome with associated sensory motor axonal neuropathy. Am J Med Genet A. 2015; 167(6):1300-4.

Drévillon L, Megarbane A, Demeer B, Matar C, Benit P, Briand-Suleau A, et al. KBP-cytoskeleton interactions underlie developmental anomalies in Goldberg-Shprintzen syndrome. Hum Mol Genet. 2013;22(12):2387-99.

Goldberg RB, Shprintzen RJ. Hirschsprung megacolon and cleft palate in two sibs. J Craniofac Genet Dev Biol. 1981;1(2):185-9.

Hurst JA, Markiewicz M, Kumar D, Brett EM. Unknown syndrome: Hirschsprung's disease, microcephaly, and iris coloboma: a new syndrome of defective neuronal migration. J Med Genet. 1988;25(7):494-7.

MacKenzie KC, de Graaf BM, Syrimis A, Zhao Y, Brosens E, Mancini GMS, et al. GoldbergShprintzen syndrome is determined by the absence, or reduced expression levels, of KIFBP. Hum Mutat. 20202020 Nov;41(11): 1906-17.

Murphy HR, Carver MJ, Brooks AS, Kenny SE, Ellis IH. Two brothers with GoldbergShprintzen syndrome. Clin Dysmorphol. 2006;15(3):165-9.
Richards S, Aziz N, Bale S, Bick D, Das S, Gastier-Foster J, et al. Standards and guidelines for the interpretation of sequence variants: a joint consensus recommendation of the American College of Medical Genetics and Genomics and the Association for Molecular Pathology. Genet Med. 2015;17(5):40524.

Salehpour S, Hashemi-Gorji F, Soltani Z, Ghafouri-Fard S, Miryounesi M. Association of a Novel Nonsense Mutation in KIAA1279 with Goldberg-Shprintzen Syndrome. Iran J Child Neurol. 2017;11(1):70-4.

Valence S, Poirier K, Lebrun N, Saillour Y, Sonigo $\mathrm{P}$, Bessières $\mathrm{B}$, et al. Homozygous truncating mutation of the KBP gene, encoding a KIF1Bbinding protein, in a familial case of fetal polymicrogyria. Neurogenetics. 2013;14(34):215-24.

Webster W. Embryogenesis of the enteric ganglia in normal mice and in mice that develop congenital aganglionic megacolon. J Embryol Exp Morphol. 1973;30(3):573-85. 